УДК $681.513+519.71+534.2$

\title{
ТЕОРИЯ ПРИНЯТИЯ РЕШЕНИЙ КАК ОСНОВА УПРАВЛЕНИЯ СЛОЖНЫМИ СИСТЕМАМИ
}

\author{
Волков В.Э., канд. физ.-мат. паук, доцент, Макоед Н.А., канд. пед. наук, доцент \\ Одеская национальная академия пищевых технологий, г. Одесса
}

\begin{abstract}
Рассиотрены проблемы принятия реиений в условиях неопределенности (на базе нечеткой логи Показано, что именио такая модель принятия ремений наиболее эфффккпикиа для управления сложнь системани.

Problems for the decision making under uncertainty (on the base' of the (fuzzy model》) are considered. It's pro that such model of the decision making is the most effective one for the complicated systems control.

Ключевые слова: система, системный анализ, принятие решений, классическая модель принятия решен принятие решений в условиях неопределенности, принятие решений в условиях риска.
\end{abstract}

В литературе [1-7] приведен ряд разнообразных определений системы вообще и сложной систем1 частности. Это - базовые определения системного анализа и теории систем, которые, как и основі определения в любой области научных знаний, не могут быть аб́солютно строгими, так как являются настол элементарными и абстрактными, что не могуг быть выражены через более абстрактные понятия. В дальнейц под системой понимается совокупность взаимосвязанных элементов, обособлснная от внсшней среды, взаимодействуюшая со средой как единое целое [7]. В свою очередь под сложной системой понимає упорядоченное множество структурно взаимосвязанных и функционально-взаимодействугоих разнотип снстем, которые объединены структурно в целостный объект функционально разнородными взаимосвязями достижения заданных целей в огределенных условиях[1]. При этом, вообще говоря, понятие «сложн системы не совпадает с понятием «большой» системы, хотя четкой границы межу этими терминамн нет [7].

В теории систем $[2,6,7]$ большой системой (large scale system) называют систему, которая состоит большого количсства взаимосвязанныг и взаимодействующих элементов и способна выполнять слож функции. При этом, однако, не всегда такая система звляется сложной. Например, с точки зре термодинамики идеальный газ [8] является весьма простой систсмой (интересно, что все двухпараметричес термодинамические системы, - а именно такой системой как раз является идсальный газ, - носят назва простых систем [8] ), в то время как он вполне подпадает под определение большой систсмы, приведен выше. Гомогенная идеальная (невязкая) жидкость, хоть и является «большой) системой, весьма проста система с точки зрсния мсханики сплошных сред [9]. Основная причина того факта, что указанныс в большие системы нельзя считать сложными, состоит в том, что эти системы состоят из однородных элемег (идеальный газ - из одинаковых молекул, взаимодействие межу которыми осушествляется только посредст их соударения, а гомогенная идеальная жидкость - 13 одинаковых жидких частиц, между слоями которы: действуют силы внутреннего трения), хотя количество этих элементов очень велико. Один из основ признаков сложной системы - некоторая «разнородность» состава, «разнотипность» составляюг существенным образом усложняюшая математическое описание системы.

Собственно говоря, способ и возможности математического описания системы ряд специалистов счи критерием для определения ее «сложности». Например, английский специалист в области кибернетики С. (Beer) $[7,10]$ все кибернетические системы разделил на простые и сложные в зависимости от способа описа. детерминированного или теоретико-вероятностного. Российский (советский) математик, инженер-адмирал Берг $[7,11]$ классифицировал все кибсрнетические снстсмы как простыс или сложные в завнсимости от спо описания: сложную систсму можно описать не менес чем двумя математичсскими языками.

Современные автоматизированные системы управления (АCУ) обеспечивают выполнение функ управления на базе использования математнческих методов и современных средств обработки информа. Важнейшей составляющей процесса управления является принятие решений. В настоящее время достижен области компьютерной и телекоммуникационной техники значительно расширили возможности челове области принятия более качественных решений в различных областях его деятельности. Это вызы необходимость создания программно-технических систем, позволяющих лицу, принимающему решение (J построить информационную технологию, способную поддержать процесс формирования того или и решения (действия) в различных ситуациях. Такая компьютерная система (КС), которая предостав поддержку ЛПР в процессе принятия решсний именуется системой поддержки принятия решений (СППР) При этом следует отметить, что в термины «принятие решений» и «поддержка» вкладываются разлиг понимания [12-14]. Создание СППР можно считать одной из проблем синтеза искусственного интеллекта, понимать под ним свойство автоматических и автоматизированных систем брать на себя отдельные фун интеллекта человека.

Принятие решения - это сложная мыслительная человеческая деятельность, которую можно опреде как выбор направления действия для достижения цели [15]. Для описания этой дсятельности существуют модели принятия решения [15]: 
1) классическая;

2) поведенческая (по Саймону).

В классической модели ЛПР с помощью действительнозначной функции вынгыпа назначает каждой альтернативе некоторое действительное число. Не составляет труда выбрать альтернативу, когда каждой из альтернатив ставится в соответствие единственный вынгрыш: выбирается, естественно, альтернатива с максимальным выигрышем. Это называется прннятием решения в условиях определснности. Проблема, однако, cocroнт в том, что ЛІР часто не обладает полным знанием о состояниях природы (среды), тогда каждой альтернативе назначастся несколько вынгрышей: имснно такая ситуация обычно возникает при управленин сложными снстемами [16].

Собственно говоря, классическая модель принятия решений применима лишь в тех случаях, когда удается постронть адекватную математическую модель системы, исходные данные для расчетов «четко» заданы (определены или измерены), а сами расчеты могут быть результативно произведсны методами классической матсматики (точное рсшение) или численного анализа (приближенными методами с любой, заданной наперед точностью). В кгассической модели принятия решений находят свое прнменение самые разнообразные разделы и методы математической науки - вариационное исчнсление и классические методы оптимизации (оптимальное управление), теория графов и комбинаторика, линейное и нелинейное программированне, теория обыкиовснных дифференциальных уравнсний и дифферсниильных уравнений с частными производными.

В тех многочислснных случаях, когда ЛПР не обладает полным знанием о состояниях природы (среды), тогда каждой альтсрнативе назначастся нссколько вынгрыпй. Выбор в такнх условиях называется принятием решений ипи в условиях риска (на основе теорин вероятностсй), или в условиях неопределенности (на базе теорни нечетких множеств н нечеткой логики $[15,17])$. Очевидно, что принимать решения в условиях риска или неонеделенности как правило прнходится при угравленин сложными системами.

Гринятие решений в условиях рнска (на базе теории вероятностей и математической статистики) - хорошо гзученный вопрос [18]. Особенно широко в этом случае применяются геория игр, вероятностное динамическое программирование, вероятностные модели управления запасами, теория массового об́служивания, имитационное моделирование, марковские процессы иринятия решений.

Долгое время принятие решений в условиях риска было единственной альтернативой классической модели принятия решений (хотя подобные термины вошли в употребление относительно недавно). Ситуация принлипиально измснилась с появлением теорин нечстких множеств и нечсткой логики [15, 17, 19-21]. Именно нсчсткая логика стала матсматичсской базой для принятия решений в условиях неопределснности.

Приняте решений в условиях неопределенности с оцной стороны стало революционным скачком в обцей теорин принятия решений, но, с другой стороны, породило серию новых проблем.

В самом деле. принлтие решений в условиях риска в ряде случаев не представляется возможным, так как оно ограничено применимостью вероятностньх моделей. Класснческос определение вероятности сводится к отнопению члсла благоприятиых исходов $A$ соб̆ытия к об́щему числу исходов $B$ [22]. Однако для ряда задач величину $A$ или величину $B$ (а иногда и обе эти величины) не только сложно вычислить, но даже нсвозможно определить. В качестве примера можно навести задачу оценки взрывоопасности некоторых объектов [23-25]. Кроме того, формальное применение модели гринятия решений в условиях риска в некоторых случаях гриводит к ошибочным результатам (см. ниже). Если же принятие решеный в условня огределенности и в условия риска невозможно, то можно применить модсль принятия решений в условиях неопределснности, которая (с известными оговоркамн) так или иначе применима практически во всех задачах.

С другой стороны, существует большое количество классов задач прннятия решений, в которых классическая модель непрнменима, но применимы модели принятия решений как в условиях риска, так и в условиях неопределенности. При этом возникает ироблема, какую из моделей следует применить для получення более точного, - а иногда и иросто верного, - резульгата. Решенню этой проблемы отчасти посвяшена настояшая работа. К тому же рассмотрен вопрос о повышении эффективности модели принятия решений в условиях неопределенности для управления сложными системами.

Рассмотрим ситуации, когда принятие решений в условиях риска является результативным и эффективным. В первую очередь к ним относятся разнообразные экономические проб̆лемы и задачи управления персоналом $[18,26]$. Во всех подобных снтуациях рассмагривалось управление большимн системами, которые, ввиду своей “однородности», подчинялись статистическим закономсрностям, однако не всегда подпадали под приведенное выше определенс сложной снстемы. Впрочем, то же относится и к большим системам, не связанным с зкономикой. Всю статистическую термодинамику, например, можно рассматривать как инструмснт для принятия решений по управлению большими термодннамическими системами (скажем такимн, как идеальный газ), причем хотя принятие решений осуцествляется в известном смысле в условиях риска, оно чрезвычайно эффективно, причем эффективность обусловлена именно тем, что система большая: пользуясь терминологией [7], се можно назвать суперснстемой.

Рассмотрим тспсрь ситуацию прияятия решения, связанную с прогнозированисм результата игры футбольного матча мсжду командами, многократно встрсчавшимися ранее. Прогноз на основе статистических данных может быть неточным, а принятое на базе этого прогноза решение, связанное, например со ставкой на футбольном тотализаторе, - совершенно ошибочным. Таким образом, модель принятия решений в условиях риска в данном случае представляется малоэффективной. Однако прогноз, сделанный футбольным экспертом, знаюшим примерный состав команд на игру, фнзичсскос и моральнос состояние игроков и т. п., может быть 
весьма точным. Таким образом, в данғом случае модель принятия решений в условиях нсопределенно (правда, с привлечением одного или нескольких экспертов) весьма эффективна. То же относитс прогнозированию погоды «на следующий день» и т.п.

В приведенных выше примерах с прогнозированием итога спортнвных состязаний или пого рассматриваются по-настоящему сложные, «неоднородные» системы. Поэтому в данном случае эффектив использование модели принятия решений в условиях неопределенности, однако для принятия решения требуется система экспертных оценок и/или «модель» самого эксперта.

Проблематичность принятия решения в условиях неопределенности, однако, также вполне очевидна. таком принятии решений проблема, как правило, слабо структурирована и формализации поддаются ль отдельные фрагменты общей постановки задачи; исходная информация засастую неполна и/или противореч। По этим причинам корректность принятого решения во многом зависит от подчас весьма суб́ъектив экспертных оценок.

На наш взгляд единственный способ избежать эту типичную проблему, возникающую при приня решений в условиях неопеделенности, связан с «нечеткой» аптроксимацией исходной проблемы некото более простой проблемой, поддающейся однако решению методами классической математики. На б полученного таким образом «классического» решения строятся соответствующие функции принадлежност функции значений нечетких логических переменньг, позволяющие принимать относитсльно объектив решения в условиях неопределенности.

Рассмотрнм следующий практический прнмер.

При проектировании газопроводов и различных типов двигателей следует определить диамегр трубы ширины канала, подбирая эти параметры таким образом, чтобы развитие детонации в трубе или в канале б. невозможным или, наоборот (в детонационных двыгателях), детонация могла распространяться без срыва по пинциирования.

Проблема распрострпнения и инициирования детонации тесно связана с проблемой структ детонационной волны. Эта проблема не может быть решена не только методами классической математики, вычислительными методами, а в ряде случаев не допускает даже корректной математической постано Задача Коши (задача с начальными условиями) для системы дифференциальных уравнений газовой динамик химической кинетики, опнсываюцей детонационный процесс, в подавляющем большинстве слу некорректна - нарушается условие единственности решения. Даже если предположитл, что каким-то обра удастся выделить все классы решений задачи Коши и проанатизировать их, - что само по себе чрезвыча сложно и вряд ли возможно на современном этапе развнтия математикн, - полученный таким обра результат не вполне применим, так как для многих практических случаев неизвестен точный вид уравне химической кинетики и «нечетко» определены некоторые термохимические параметры.

Однако проблема распространения детонашии, рассмотренная с упроценных позиций тсо гидродинамической устойчивости, позволяет относительно точно рассчитать пульсационнуго структ детонационной волны $[27,28]$. При этом по диаметру трубы нли по ширине канала укладывается целое чи неоднородностей (детонационных ячеек), которое может быть найдено аналитически (таким обра рассчитываются режимы одноголового, двухголового и многоголового детонационного спина). Если диам трубы или ширина канала превышает расчетный размер одной неоднородности (ячейки), то должен произо срыв детонации. Таким образом определяется критический диаметр трубы или критическая ширина канала минимальный поперечный размер, при котором детонация еше возможна.

С целью пириняия решения в условиях неопределенности можно ввести в рассмотрение нечс высказывание $\bar{D}$, выражающее превышение шириной канала или диаметром трубы размера детонацион ячейки. Функция принадлежностн $\mu_{D}$ для нечеткой переменной $\bar{D}$ имеет кусочно-линейный вид, задан формуламг1

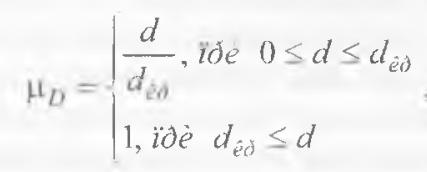

где $d$ - диаметр канала ици ширина трубы.

Формула (1) может служить основой для гринятия решения в условиях неопределенности, но не тре субъективных экспергых оценок: величина $d_{\kappa p}$ определяется неточно, но на базе строгой - хотя и вес упрощенной - теории.

Итак, для управления так называемыми сложными системами применение модели принятия решени основе нечеткой логики иногда весьма эффективно в сочетании с классической моделью. Свидетельством т может служить анализ проблем управления взрывобезопасностью промышленных и транспортных объе [25], которые с точки зрения системного анализа безусловно являются сложными системами. Результ вычисления значений нечеткпх логических выражений, составленных как композиция различ конъюнктивных и дизъюнктивных форм [23,25] позволяют оценить возможность взрыва, а также взрывного процесса, и принять соответствугщие решение по предотвращению взрыва или подавле взрывных волн уже на стадни проектирования обтекта или в оперативном режиме. 
Нечеткая логика позволяет формальным путем получить ряд парадоксальных на первый взгляд, но вполне объяснимых оцснок взрывобезопасности.

Например, несоблюдение в нечеткой логике правила исключенного третьего [17,20] и ряда следсгвый из этого правила формально приводит к достаточно необычному выводу о том, что уровень максимальной взрывоогасности объекта не всегда соответетвует уровню его максиматьной пожароопасности. Данный парадокс, однако, разрешается с точки зрения физнки горения и взрыва довольно просто: пожар (относительно медленный, хотя в известной мере неконтролируемый процесс горения) и взрыв (почти мгновенное и локализованное в гространстве неконтролируемое выделение большого количества энергии) - суть явления одной природы; вполне очевидно, что если среда вообце не пожароопасна, она не является также и взрывоопасной, однако пожар далеко не всегда переходит во взрыв, поэтому возможны ситуации когда эвснтуальная возможность возникновения пожара весьма высокая, но вероятность персхода такого пожара во взрыв низкая или вообще отсутствует; последний факт как раз и означаст низкий уровень взрывоопасности среды. Кроме того, в ряде сред [29-31] взрыв (детонация) может быть инишиирован, минуя стадию пожара.

Вышензложенное ириводит к следуюцим выводам:

1. Классическая модель принятия решений для управления большими и сложными системами в ряде случаев непрнменнма.

2. Для управления большими «однородными» системами предпочтительнсе выглядит модель принятия рсшений в условиях риска.

3. Для управления сложными «неоднородішми» системами модель принятия решений в условыях неопрделенности в большинстве ситуаций - единственная адекватная результативная модель.

4. Корректность применения модели принятия решений в условиях неоиределенности резко повышается, если эта модель сочетается с классической моделью приняти решений. Применение последней требует упроцения математической модели самой сложной системы.

\section{Литература}

1. Монсеев Н.Н. Математические задачи системного анализа. - М.: Наука, 1981. - 490 с.

2. Денисов А.А., Колесников Д.А. Теория больших систем улравления. - Л.: Энергонздат, $1982 .-288$ с.

3. Дмитрнев А.А., Мальцев П.А. Основы теории построення н конструирования сложных систем. - JI.: Энергоатомиздат, 1988. - $192 \mathrm{c}$.

4. Перегудов Ф.И.. Тарасенко Ф.П. Введение в системный анализ. - М.: Высшая школа, $1989 .-367$ с.

5. Стопакевич О.А. Теорія систем і ситемний аналіз. - К.: ICДО, 1996. - 200 с.

6. Острейковский В.А. Теория систем. - М.: Высшая школа, 1997. -240 с.

7. Ладанюк А.П. Основн системного аналізу. - Вінниця: Нова книга, 2004. - 176 с.

8. Беляев Н.М. Термодннамика. - К.: Вища шк. І оловнос изд-во, 1987. - 344 с.

9. Седов Л.И. Механнка сплонной среды. Т. 1. - М: Наука. Гл. ред. физ.-мат. лит., 1983. - 528 с.

10. Джордж Ф. Основы кибернетики. - М.: Радио и связь, 1984. -272 с.

11. Бородин А.Н., Бугай А.С. Выдающиеся математики: Бнографический словаръ-справочник. - К.: Рад. шк., 1987. $-656 \mathrm{c}$.

12. Михалевич В.С., Волкович В.Л. Концепция построения основных функциональных подсистем системы поддержки приняткя репений //Автоматика. - 1993. - №5. - С.3-13.

13. Keen P.G.W. Decision Support Systems: Next Decade // IFIP Conference, - 1986. - P.21-26.

14. Hopple G.W. The State of the Art in Decision Suppon Systems. - QED Information Sciences, Inc., 1988. - 246 p.

15. Энта Ё. Теория нечетких решений: Нечеткие множества 11 теория возможностей. Последние достижения Под ред. Р.Р. Ягера. - М.: Радио 11 связь, 1986. Часть IV. ГІрактические задачи. - С. 301-312.

16. Добкин В.М. Системный анализ в управленин. - М: Химия, 1984. - 224 с.

17. Мелихов А.Н., Бернштейн Л.С., Коровин С.Я. Ситуационные советующие системы с нечеткой логикой. М.: Наука. Гл. ред. физ.-мат. лит., 1990. - 272 с.

18. Таха Х. Введсние в исследование операций. - М.: Нздатсльский дом «Вильямс», 2001. - 912 с.

19. Zadeh L.A. Fuzzy Sets. // Information and Control, 1965. - Vol. 8. - P. 338-353.

20. Заде Л. Понятие лингвитической переменной и его применение к принятию приближенных решений. - М: Мнр, 1976. - $165 \mathrm{c}$.

21. Нечеткие множества и теория возможностей. Последние достижения/ Под ред. Р.Р. Ягера. - М.: Радио и свизь, 1986.- $408 \mathrm{c}$.

22. Справочник по высшей математике /Бронштейн І1.Н., Семендяев К.А. - М: Наука. Гл. ред. физ.-мат. јгит., 1979. $-832 \mathrm{c}$

23. Волков В.Э., Макоед Н.А. Теория нечетких множеств в экспертных системах поо вогросам взрывобезопасносп // Тез. докл. международной научно-практической конференции «Пищевые технологии-2006». - Одесса. - 2006. - С. 157.

24. Волков В.Э. Интеллектуальные системы подцержки принятия решений по вопросам взрывобезопасности // Зернові продукти і комбікорми, 2007. - №2, червень 2007. - С. 44-47.

25. Волков В.Э., Жуковский Э.Н. Проблемы управления взрывобезопасностью промышенных и транспортных объектов // Доклады XV-ой международной научной конференции по автоматическому управлению 
«Автоматика-2008», 23-26 сентября 2008 г., Одесса, Украина. В 3-х томах. Т.1.Одесса: ОНМА, 2008. - С.9699.

26. Ларичев О.И. Наука и искусство принятия решений. - М.: Наука, 1979. -200 с.

27. Асланов С.К., Волков В.Э. Неустойчивость и структура детонации в схематизированной камере сгорания // Химическая физика, 2005. - Т. 24, № 7. - С. 86-90.

28. Асланов С.К., Волков В.Э. Неустойчивость и инициирование детонации // Тез. докл. ХІІ-го Симпозиума по горению и взрыву. - Черноголовка, Российская академия наук. - 2005. - С.129.

29. Дрёмин А.Н., Савров С.Д., Трофимов В.С., Шведов К.К. Детонационные волны в конденсированных средах. - М.: Наука, 1970.

30. Взрывные явления. Оценка и последствия: В 2-х кн. Кн.І / Бейкер У., Кокс П., Уэстайн ПІ. и др. - М: Мир, 1986. $-319 \mathrm{c}$

31. Зверев И.Н., Смирнов Н.Н. Газодинамика горения. - М.: Изд-во МГУ. - 1987.-307с.

\title{
ОСОБЕННОСТИ УПРАВЛЕНИЯ ТЕХНИЧЕСКИМИ ОБЪЕКТАМИ НА ТРАЕКТОРИИ РАСХОДОВАНИЯ РАСЧЕТНОГО РЕСУРСА
}

\author{
Воинова С. А., к.Т.н., доцешт \\ Одеская национальня академия пишевых технологий, г. Одесса
}

Нзложень особениости упрабления техническими объектами на траектории расходокания расчетного pecypa.

The features of control of technical objects on a pathway of spending of a design resource are stated.

Клочевье слова: угравление, технический объект, траектория, расходование, ресурс.

Технологические свойства технического объекта (ТО) на его траектори1и расходования ресурса (ТРР) непрерывно изменяются от свойств нового объекта до свойств объекта, изношенного, перешедшего в предельное состояние. Этим изменениям подвержены также регулировочные свойства (РС) ТО - параметры н характеристики - как объектов управления.

Технологичсскуло эффективность ТО формиругот ее составлягшие - экологическая, экономичсская и обшетехническая эффективность. Экологическая эффективность (ЭлЭ) является главным показателсм (критерием) степени совершенства ТО [1-3]. Далее будем использовать ее в качестве объекта анализа.

В экологических свойствах ТО заложены экологические возможности используемой технологии и возможности выполненной конструкция. САУ позволяет реализовать указанныс свойства ТО в его фактическую ЭдЭ

Новый ТО оснацают системой автоматического управления (САУ), регулятор которой настраивают на алгоритм, адекватный РС нового объекта и предназначенный для поддержания исходной ЭлЭ - ЭлЭ и (рис. 2). В гипотетическом случае, когда ТО не изнашивается, его ЭлЭ не изменяется во времени, остается на уровне ЭлЭ как угодно долго: график «а - b» (рис. 2). Применительно к подобному ТО понятие «ресурс» уграчивает смысл. Если рассуждать формально, то условный ресурс подобного ТО бесконечно велик. У реального же ТО с течением времени, вследствие износа, его РС изменяются. Это обусловливает непрерывнос снижение его ЭлЭ до уровня потенциальной - ЭлЭ - график «а - с» (рис. 2).

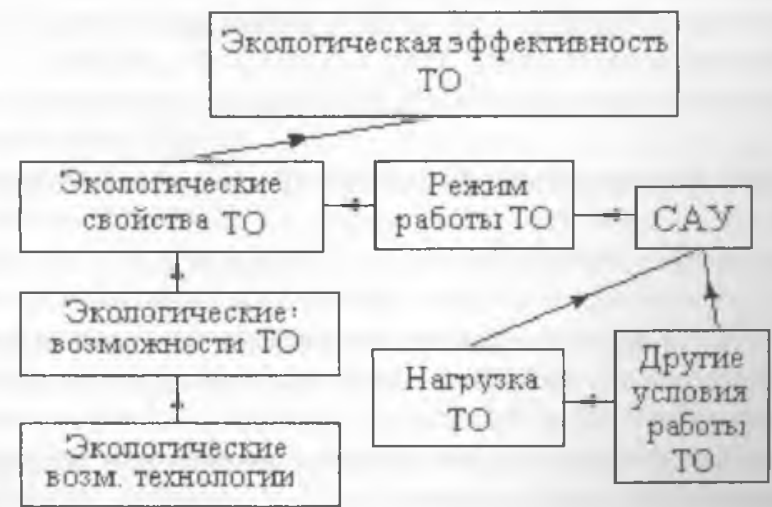

Рис. 1 - Структурно-логическая схема взаимодействия факторов, влияющих иа экологическую эффективность ТО 